\title{
Personal repertoire of travel modes and mode change potential
}

\author{
N. Karasmaa \& V. Voltti \\ Linea Consultants Ltd., Finland
}

\begin{abstract}
This paper presents research concerning people's personal repertoire of travel modes. The repertoire is studied from the viewpoint of how committed people are to using a certain travel mode or a combination of travel modes. Also the objective was to look into the reasons for, and background of, people's choices. Based on the survey, respondents were profiled to five mover groups according to how committed they were to using certain travel modes. These groups were heavy car users $(12 \%)$, car users $(30 \%)$, regular customers of public transport (22\%), people who prefer walking or cycling (14\%), and people who mix all modes $(22 \%)$. For any individual trip purpose that was studied about half of the respondents used only one travel mode. One third of the respondents had a dominant mode, but they used also other modes and one fifth had two or more equally common travel modes.
\end{abstract}

Keywords: mobility management, public transport, mode choice.

\section{Introduction}

The objective of the research was to examine how committed individual travellers are to using a certain travel mode or a repertoire of travel modes. The survey aims to ascertain the extent to which people use different travel modes by addressing questions such as: What proportion of public transport users also use other modes regularly or occasionally? What travel modes do different groups of people consider as relevant alternatives, given a potential for choosing between the alternatives? These involve further questions, for example: What proportion of regular car drivers never use public transport in any circumstances? For what proportion of car drivers is the competitiveness of public transport a relevant factor? 


\section{Data and method}

The research was based on the travel-behaviour data collected in the Helsinki metropolitan area in 2005. The mail-back survey was made for 3000 inhabitants aged over 17 years. The response rate was 36.5 which means that the number of acceptable interviews was 1092. Essential part of the mail-back form was the table designed to collect data concerning peoples travel behaviour habits (Figure 1). This table provided with data that described travel mode choices in general rather than concerning one individual trip or trips on a certain day. The trip groups studied were daily trips to work, grocery-shopping trips, other shopping trips, free-time trips made regularly and other free-time trips. People were also asked about their socio-economical information (age, sex, family type, car ownership, etc.) and about their preferences and opinions of many subjects related to the matter.

Based on travel mode choices, respondents were profiled to five mover groups according to what travel modes they used and how committed they were to using them. Socio-economical properties of the mover groups were studied and the choices and values - opinions concerning environmental issues, for example - of people were considered according to the mover group they belong to.

\section{What modes of transport do you use in winter on trips shown below? (You can choose multiple modes, but do not tick a mode that you use only seldom. There were a few additional instructions like this, the rest are omitted from this example.)}

\begin{tabular}{|l|l|l|l|l|}
\hline \multirow{2}{*}{$\begin{array}{l}\text { Daily trips to work } \\
\begin{array}{l}\square \text { hardly ever do } \\
\text { these trips }\end{array}\end{array}$} & \multicolumn{1}{|c|}{ car or taxi } & $\begin{array}{c}\text { public } \\
\text { transport }\end{array}$ & \multicolumn{1}{c|}{ bicycle } & \multicolumn{1}{c|}{ walk } \\
\cline { 2 - 5 } & $\begin{array}{l}\square \text { almost always } \\
\square \text { quite often } \\
\square \text { occasionally }\end{array}$ & $\begin{array}{l}\square \text { almost always } \\
\square \text { quite often } \\
\square \text { occasionally }\end{array}$ & $\begin{array}{l}\square \text { almost always } \\
\square \text { quite often } \\
\square \text { occasionally }\end{array}$ & $\begin{array}{l}\square \text { almost always } \\
\square \text { occaite often } \\
\text { occionally }\end{array}$ \\
\hline
\end{tabular}

\begin{tabular}{|l|l|l|l|l|}
\hline \multirow{2}{*}{$\begin{array}{l}\text { Grocery-shopping } \\
\text { trips }\end{array}$} & \multicolumn{1}{|c|}{ car or taxi } & \multicolumn{1}{c|}{$\begin{array}{c}\text { public } \\
\text { transport }\end{array}$} & \multicolumn{1}{c|}{ bicycle } & walk \\
\cline { 2 - 5 } $\begin{array}{l}\square \text { hardly ever do } \\
\text { these trips }\end{array}$ & $\begin{array}{l}\square \text { almost always } \\
\square \text { quite often } \\
\square \text { occasionally }\end{array}$ & $\begin{array}{l}\square \text { almost always } \\
\square \text { quite often } \\
\square \text { occasionally }\end{array}$ & $\begin{array}{l}\square \text { almost always } \\
\square \text { quite often } \\
\square \text { occasionally }\end{array}$ & $\begin{array}{l}\square \text { almost always } \\
\square \text { occasite often } \\
\text { occally }\end{array}$ \\
\hline
\end{tabular}

(... other shopping trips, regular free-time trips, other free-time trips.)

Figure 1: An example of the questionnaire.

\section{Results}

Two hundred and thirty seven different mode-choice combinations (from the 256 theoretically possible) were found during the study. To aggregate the data, typically, only a so-called main mode and the presence of secondary modes were considered, not taking into account what the secondary modes were. The most 
common combinations included only one mode, which was used almost always for a certain trip purpose. When making grocery store trips, this mode was car or walking. When making other trips, car and public transport were the most popular modes.

Approximately half of the respondents used only one mode for a certain trip purpose. Approximately one third of respondents used more than one mode, but a so-called main mode that was used more often than others could be identified. For $20 \%$ of respondents it was not possible to define any one predominant main mode. For these respondents a so-called combination-mode was used, for example, the main mode could be "car or bus". This kind of mixed use of different modes was equally common in every trip group. Shares of mode choice combinations, in other words travel mode repertoires, on daily trips to work are shown in Figure 2.

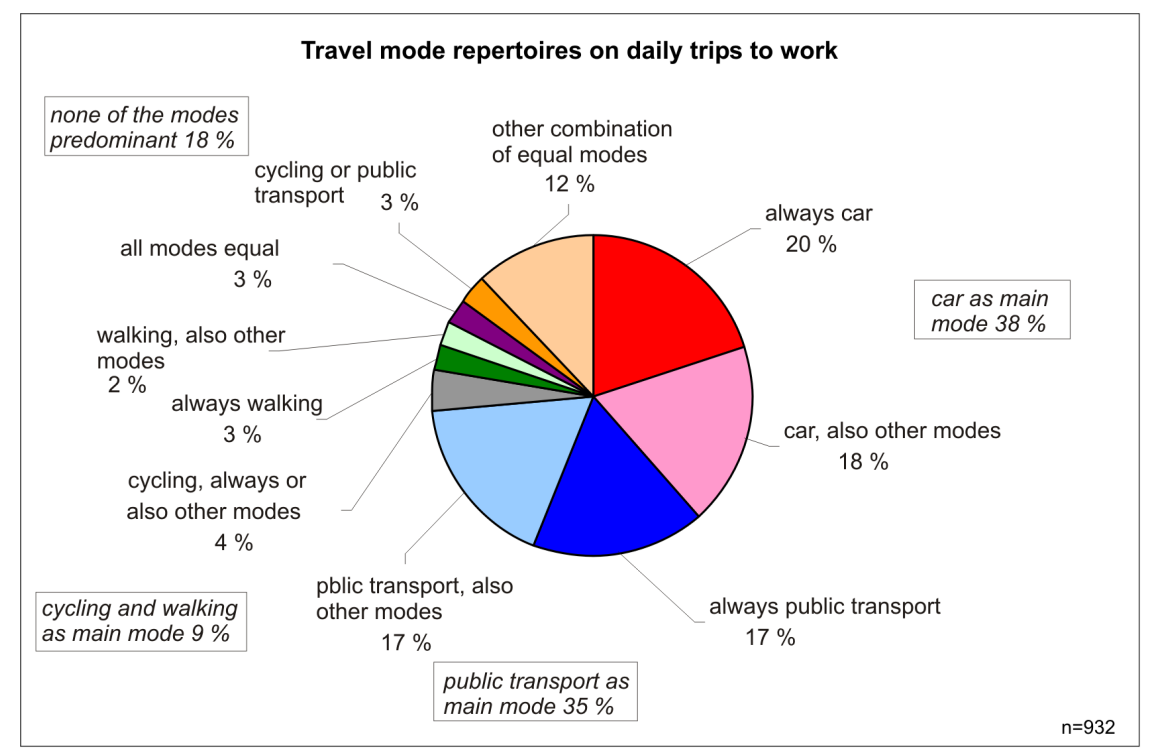

Figure 2: $\quad$ Shares of travel mode repertoires on daily trips to work.

When considering all trip purposes, approximately one third of all respondents were highly committed to using one typical repertoire of travel modes for all of their trips. Approximately $30-40 \%$ of respondents used a travel mode repertoire typical for them on most trip types, but not on all. For $30-55 \%$ of the respondents the travel mode repertoire varied depending on the trip group and situation. Of those who were committed to one main mode of travel, $80 \%$ were car users. Of all respondents, $20 \%$ reported that they do not use public transport at all. Of car users, this percentage was 43.

For comparison, the "traditional" mode shares for trips to work in Helsinki metropolitan area are: walking and cycling 15\%, public transport 39\% and car $46 \%$ of trips. 
Based on the survey, respondents were profiled to five mover groups according to what travel mode repertoire they were accustomed to use and how committed they were to using it. These groups were heavy car users $(12 \%)$, car users $(30 \%)$, regular customers of public transport $(22 \%)$, people who prefer walking or cycling (14\%), and people who mix all modes $(22 \%)$.

For heavy car users car is the sole main travel mode for all trip purposes. Furthermore heavy car users hardly ever use bicycle or public transport. For car users car is usually the sole main travel mode. Regular customers of public transport and people who prefer walking or cycling are defined respectively. People who mix all modes use car, public transport and either cycling or walking (or both) as a main travel mode. They can use a repertoire of two or more equally common travel modes or they can use a sole main mode that varies by trip type. The descriptions presented here are somewhat simplified, the exact definitions of the mover groups are more detailed.

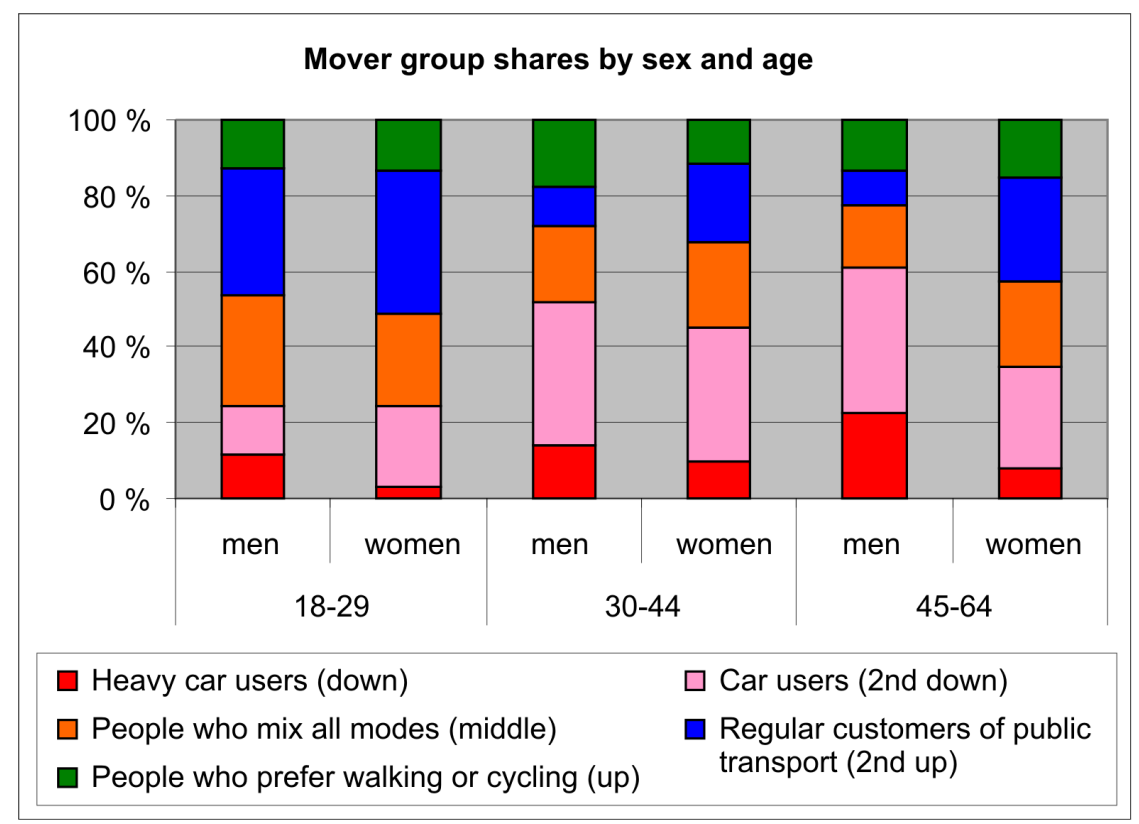

Figure 3: $\quad$ Mover groups by sex and age.

The typical heavy car user was a man aged over 45 years, living in a detached house or row house in a suburban area (Figure 3). There could be children under 18 in his family and the family usually had at least two cars. The typical regular customer of public transport was a man under 30 years of age or a woman of any age. He or she lived alone in the city centre and had no children and no car. The persons who mixed all modes were men or women of all ages and they lived in apartment blocks or row houses along public transport routes with good connections. Some of them had children aged under 18 years in the 
family and the household typically had one car. The persons who preferred walking or cycling were men or women of all ages. They lived usually alone in blocks in the city centre, but also in the suburban area. Usually this kind of household owned one car at most.

Families with children were dominating group when considering heavy car users and people who mainly used car, whereas in the group of regular public transport users there was only $16 \%$ families with children. The share of single people was highest when considering regular public users and people who preferred walking and cycling (Figure 4).

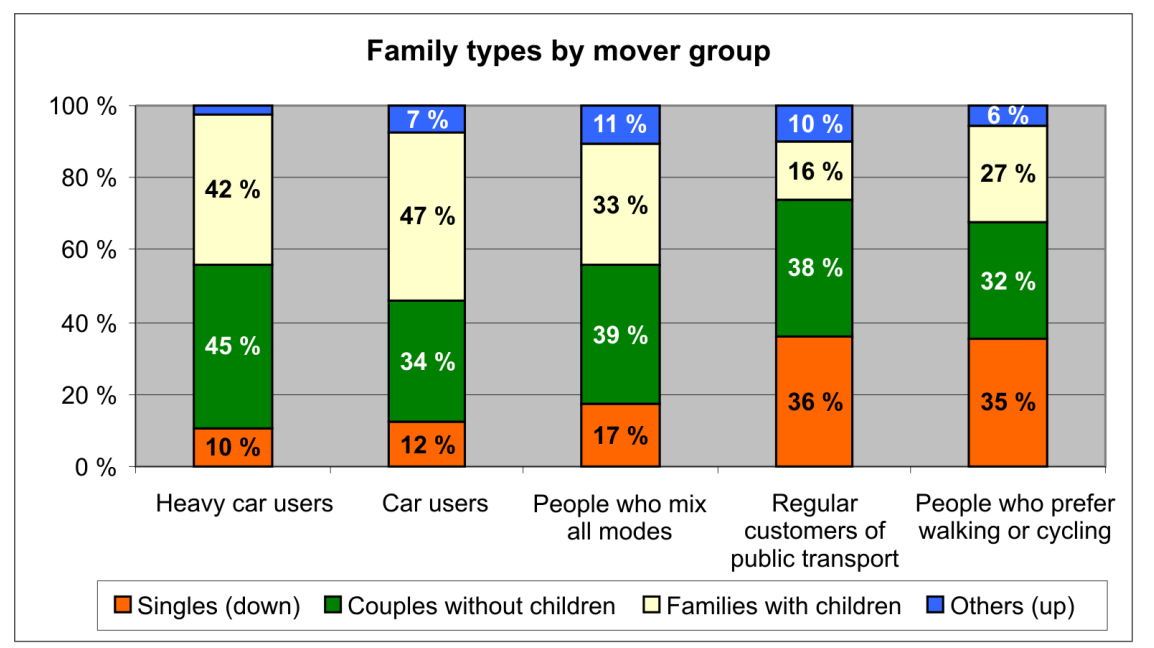

Figure 4: Mover groups by family type.

Movers were also polarised by living area (Figure 5). The share of regular customers of public transport was greater in the city of Helsinki than in the surrounding cities of Espoo and Vantaa. The share of walkers and cyclists was greatest in the city center, but also high in some suburban areas, for instance in the "garden-city" of Tapiola. Car users were highly represented in the suburban area. Especially regular travellers on public transport as well walkers and cyclists, but also people who mixed all modes indicated that they choose their living are so, that it is possible to manage without owning a car.

The most common argument for having a car in the household was that it was needed for work trips (44\%). Thirty-four percent also needed a car in his/her work. The second most common reason for having a car was that it was needed for making trips to the summer cottages. (It is quite common in Finland to have a summer cottage by a lake.) Common reasons were also the family, children, and the desirability of having a car available when needed.

Approximately only one fifth of non-car households reported that they would need a car or had planned to buy a car as soon as it is possible. On the other hand, $50 \%$ of non-car households with children were going to buy a car. 

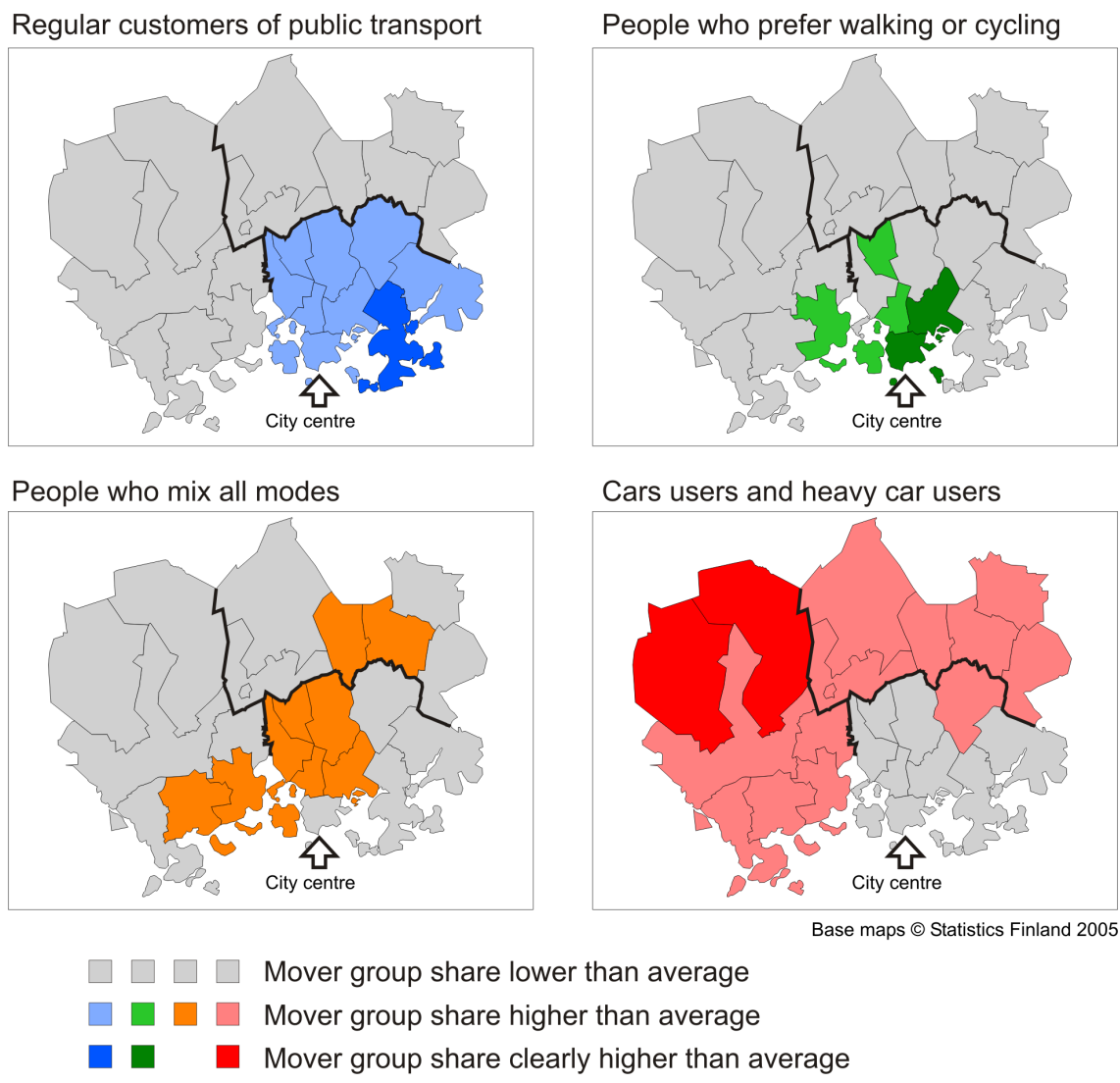

Figure 5: $\quad$ Mover group shares by living area $(\mathrm{n}=1088)$.

Heavy car users stated that they were not willing or able to decrease car use in any circumstances. However, one fifth of car users and people who mix all modes were both willing to decrease car use and also reported it to be possible. Probably, the greatest potential to decrease car use is within the car user group.

Physical exercise derived from cycling and walking highly motivated every mover group to use vehicular traffic lightly. However, less importance was given to the environment. The price was not an important factor for car users, but affected the choices of other mover groups. This means that it is possible that reducing ticket prices does not increase public transport use, but increasing prices may decrease the number of people who use public transport currently. Approximately half of the respondents considered public transport to be a cheap way to travel from one place to another.

Car users and heavy car users viewed public transport timetables and routes as not convenient for them and thought public transport was troublesome to use (Figure 6). However, walking distances to bus stops were not considered too long even in the heavy car user group and all respondents considered that public transport routes and time tables are easy to find out. Regular customers of public 
transport as well walkers, cyclist and people who mix all modes had a very positive conception of the level of service of public transport. However, emotion of insecurity was a serious problem for women. Regardless of age, $70 \%$ of women were so worried about harassment and violence that they avoided walking alone e.g., in evening times.

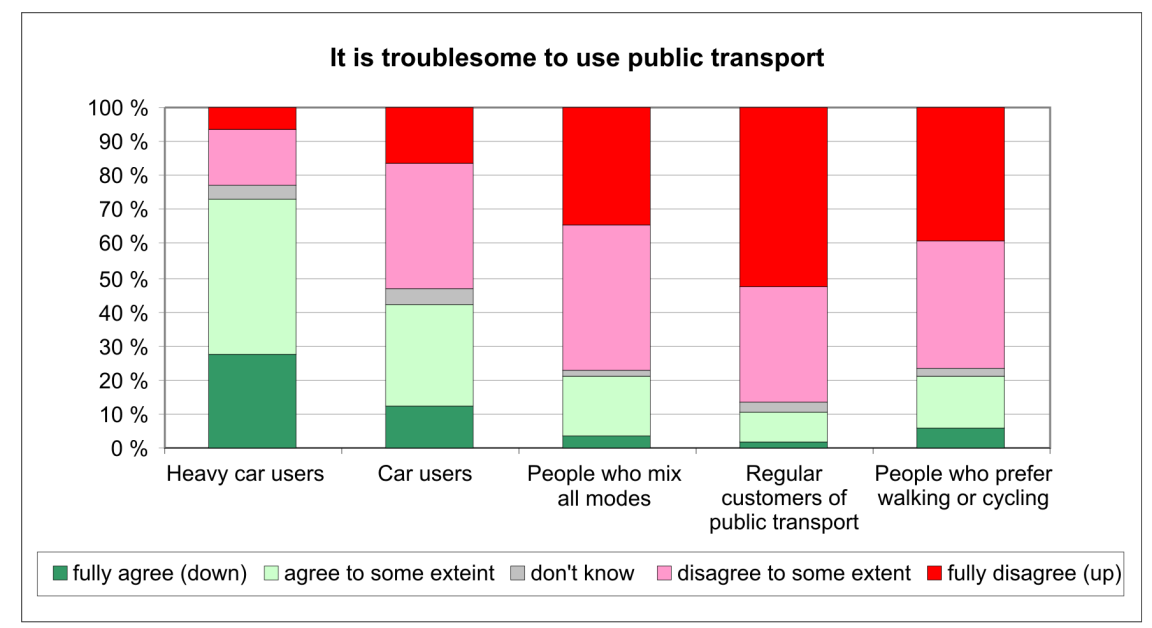

Figure 6: Opinions concerning the troublesome of the use of public transport.

\section{Conclusions}

The study shows that the very versatile ways people use different travel modes can be outlined and described with quantitative data and user profiles. The results provide a general overview of the way people use urban transport systems as a whole. This overview can be best utilized in strategic planning and marketing.

The majority of people living in the Helsinki Metropolitan Area use various travel modes and are not committed to a single one. People who are committed to single travel mode are almost always car drivers, but still also the majority of car drivers use multiple travel modes.

"It is the fusion of sustainable travel modes that can compete with the car."

\section{Reference}

[1] Voltti, V. \& Karasmaa, N., Personal repertoire of travel modes and potential for modal shift. Publications of the Ministry of Transport and Communications Finland: Helsinki, to be published 2006. 